\title{
BMJ Open Factors influencing clinical trial site selection in Europe: the Survey of Attitudes towards Trial sites in Europe (the SAT-EU Study)
}

\author{
Marta Gehring, ${ }^{1}$ Rod S Taylor, ${ }^{2}$ Marie Mellody, ${ }^{3}$ Brigitte Casteels, ${ }^{4}$ Angela Piazzi, ${ }^{3}$ \\ Gianfranco Gensini, ${ }^{5}$ Giuseppe Ambrosio ${ }^{6}$
}

To cite: Gehring M, Taylor RS, Mellody M, et al. Factors influencing clinical trial site selection in Europe: the Survey of Attitudes towards Trial sites in Europe (the SAT-EU Study). BMJ Open 2013;3:e002957. doi:10.1136/bmjopen-2013002957

- Prepublication history for this paper is available online. To view these files please visit the journal online (http://dx.doi.org/10.1136/ bmjopen-2013-002957).

Received 1 April 2013

Revised 9 October 2013

Accepted 10 October 2013

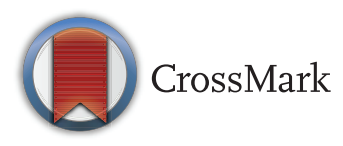

\footnotetext{
${ }^{1}$ sbg Healthcare Consulting, Lausanne, Switzerland 2Exeter Medical School, Institute of Health Services Research, University of Exeter, UK

${ }^{3}$ Virtuoso Consulting, Geneva, Switzerland

${ }^{4} \mathrm{BC}$ Consulting \& Solutions, Lausanne, Switzerland

${ }^{5}$ Division of Cardiology, University of Florence, Florence, Italy

${ }^{6}$ Division of Cardiology, University of Perugia School of Medicine, Perugia, Italy
}

Correspondence to Dr Giuseppe Ambrosio; giuseppe.ambrosio@ ospedale.perugia.it

\begin{abstract}
Objectives: Applications to run clinical trials in Europe fell 25\% between 2007 and 2011. Costs, speed of approvals and shortcomings of European Clinical Trial Directive are commonly invoked to explain this unsatisfactory performance. However, no hard evidence is available on the actual weight of these factors or has it been previously investigated whether other criteria may also impact clinical trial site selection.
\end{abstract}

Design: The Survey of Attitudes towards Trial sites in Europe (SAT-EU Study) was an anonymous, crosssectional web-based survey that systematically assessed factors impacting European clinical trial site selection. It explored 19 factors across investigatordriven, hospital-driven and environment-driven criteria, and costs. It also surveyed perceptions of the European trial environment.

Setting and participants: Clinical research organisations (CROs), academic clinical trial units (CTUs) and industry invited to respond.

Outcome measures: Primary outcome: weight assigned to each factor hypothesised to impact trial site selection and trial incidence. Secondary outcome: desirability of European countries to run clinical trials. Results: Responses were obtained from 485 professionals in 34 countries: 49\% from BioPharma, $40 \%$ from CTUs or CROs. Investigator-dependent, environment-dependent and hospital-dependent factors were rated highly important, costs being less important $(p<0.0001)$. Within environment-driven criteria, pool of eligible patients, speed of approvals and presence of disease-management networks were significantly more important than costs or government financial incentives $(p<0.0001)$. The pattern of response was consistent across respondent groupings (CTU vs CRO vs industry). Considerable variability was demonstrated in the perceived receptivity of countries to undertake clinical trials, with Germany, the UK and the Netherlands rated the best trial markets $(p<0.0001)$.

Conclusions: Investigator-dependent factors and ease of approval dominate trial site selection, while costs appear less important. Fostering competitiveness of European clinical research may not require additional government spending/incentives. Rather, harmonisation of approval processes, greater visibility

\section{Strengths and limitations of this study}

- We provide systematic evidence across a large sample of expert professionals indicating that fostering competitiveness of European clinical research may not require additional government spending/incentives. Carefully crafted harmonisation of approvals, greater visibility of centres of excellence via disease networks/the web, and reduction of 'hidden' costs are more likely to boost competitiveness of European clinical research.

- Consistent with voluntary surveys, we could only analyse responses provided by those interested in replying, and therefore cannot exclude that other points of view may have emerged from those who did not participate; our questionnaire may also have missed potentially important factors.

- Carefully crafted harmonisation of approvals, greater visibility of centres of excellence via disease networks/the web, and reduction in 'hidden' costs are more likely to boost the competitiveness of European clinical research.

of centres of excellence and reduction of 'hidden' indirect costs, may bring significantly more clinical trials to Europe.

\section{INTRODUCTION}

Europe has consistently expressed a desire to maintain and improve clinical trial competitiveness, ${ }^{1-3}$ most recently by advocating a 'European Research Area' in which 'researchers, scientific knowledge and technology circulate freely'. A major component of the European governance for clinical research, European Clinical Trial Directive 2001/20/EC (CTD) was intended to support this goal, focusing on the harmonisation of 
research processes across EU member states. ${ }^{5-9}$ However, the CTD failed to achieve its intended impact on the simplification and harmonisation of administrative provisions governing clinical trials, ${ }^{9}$ and thus on the level of European clinical research activity. ${ }^{2} 1011$ In fact, from 2007 to 2011, the number of clinical trial applications in Europe fell 25\%. ${ }^{12}$ Accordingly, although concerted calls for further CTD revisions continue ${ }^{1314}$ and recommendations awaiting member state review have been made by the European Commission ${ }^{6}$ and endorsed by scientific societies, ${ }^{15}$ it is not clear which specific recommendations should be implemented or prioritised at either national or pan-European level.

Much of this uncertainty stems from an insufficient understanding of the key drivers determining decision made by the healthcare industry, academic clinical trial units (CTUs) and clinical research organisations (CROs) in selecting European trial sites. Furthermore, although it is widely believed that costs and speed of approval are key factors influencing clinical trial incidence in Europe, ${ }^{6}{ }^{16}$ the relative weight of these and other important criteria is poorly understood. To our knowledge, no published studies have examined country and site selection criteria for trials conducted in Europe. Evidence is therefore needed to improve our understanding of stakeholders' decision-making process.

The Survey of Attitudes towards Trial sites in Europe (the SAT-EU Study) was established as a non-profit collaborative effort to systematically assess factors impacting clinical trial site selection in Europe. We also investigated whether trial selection needs differ between academic and commercial sponsors. Finally, the survey sought to explore perceptions of the current European trial environment, and to identify areas for future improvement.

\section{METHODS}

\section{Survey design}

The SAT-EU Study was an anonymous web-based crosssectional survey undertaken between 26 September 2011 and 21 January 2012. It included all stakeholder groups involved in clinical trial site selection, that is, BioPharma companies, medical device manufacturers, CROs and CTUs. The survey sought to capture information on early-phase and late-phase studies. Late-phase studies were defined as phase III for CTUs, BioPharma and their subcontractors (ie, CROs) and phase IV for other participants (eg, medical device companies).

A multistage approach was used to develop the survey. First, we identified the main criteria expected to impact site selection. Second, we organised these into four broad categories: (1) investigator related, (2) hospital/ institution related, (3) country/environment related and (4) costs (evaluated separately and within the environment category). Third, the defined criteria underwent review and discussion with a small number of knowledgeable professionals to ensure that potentially relevant criteria had not been missed (figure 1).

The study group then built an internet-based survey hosted on a freely accessible online questionnaire software (Survey Monkey, Palo Alto, California, USA).

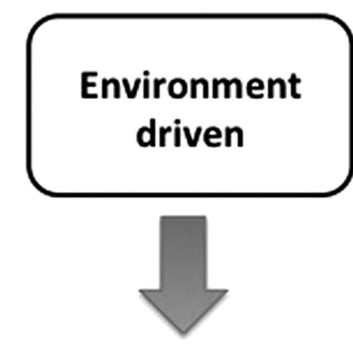

- Size of market/eligible patients in region

- Speed of MoH/Ethics approvals

- Government financial/ tax incentives

- Cost of running trials in relevant market

- Disease management system/networks

- Country on Institution's "core country list"

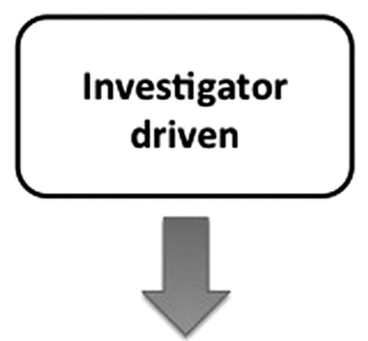

- Investigator interest

- Previous experience in similar studies

- Concurrent trial workload

- Recruitment and retention track record in prior trials

- Publication track record

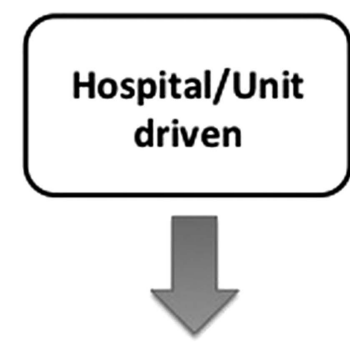

- Site personnel study experience and training

- Site personnel language capabilities

- Facilities required by trial (labs, imaging)

- Hospital Quality Assurance process

- Hospital institutional approval system/ contracts

- Respondent's previous experience w/Hospital

Figure 1 Hypothesis about trial site selection criteria. Four categories of levers potentially impacting trial site selection were identified. Survey-weighed relevance across these four levers, then drilled down for weight within each subcategory. 
Before launching the survey, healthcare market research experts (The Planning Shop International, London, UK) reviewed the survey design to optimise content and minimise bias. Additionally, a pilot survey undertaken by 15 respondents in June 2011 was used to validate and refine question content and organisation.

\section{Survey procedure}

The survey consisted of 23 questions, which took some 20 min to complete. In sequence, questions asked participants to (1) provide demographic information anonymously (2) rate the importance of each of the hypothesised trial site selection criteria for Europe as a whole, (3) provide perception of the trial environment in 12 European countries and (4) rank areas of potential improvement. Participants' feedback was assessed using a multiple-choice format, requiring respondents to provide a single response of rank. The full set of questions is accessible at http://www.sbg-marcom.ch/sat-eu/ Study_plan.html. The order of presentation of individual responses to each question was scrambled across respondents to minimise response bias. At the end of each section, a response box allowed participants to provide open text comments, available as an 'online supplement'. Results of the survey were thoroughly reviewed among the study group, and subsequently discussed with a 25-member expert panel in Brussels on November 2012.

The survey was advertised through industry and clinical trial associations, online communities, social networks and personal contacts of the SAT-EU Study group ${ }^{17}$ so that the precise number of people invited to participate is not known. No remuneration was provided to participants, but respondents were offered a summary of survey results once available.

\section{Statistical analysis}

Given the descriptive nature of the SAT-EU Study design, we did not formally estimate a required sample size. Instead, we sought to obtain at least 150 completed questionnaires from across the four stakeholder groups. Results are primarily presented descriptively as means (and 95\% CI), or medians (and upper and lower quartiles), as appropriate to show results by group or country. Where data were available, responses were compared across three survey respondent groupings (ie, CTU vs CRO vs industry), and across responses within each survey question, using one-way analysis of variance.

\section{RESULTS}

A total of 485 individual responses were obtained, with participants providing responses to $72 \%$ of questions on average. Responders represented over 100 different institutions, including over 50 pharmaceutical, biotechnology or medical device firms and over 20 CROs and CTUs.

\section{Respondent demographics}

Respondents represented over 37 countries, the top five contributors being Italy, USA, the UK, Germany and Spain (table 1). Participants were almost evenly split between BioPharma (49\%) and CROs/CTUs (40\%; figure 2). In terms of hierarchy/job description, $43 \%$ were vice president, director or manager in a research or marketing position, and an additional $20 \%$ were head of a CTU (figure 3, left panel). The majority of respondents described themselves as being directly involved in trial site selection decisions; almost two-thirds either personally headed, or sat on the trial site selection committee of their organisation (figure 3, right panel). Importantly, most respondents were the final decisionmakers, stating that they were either the 'overall final decision maker', or that trial site selection decisions were 'entirely at (their) discretion'.

\begin{tabular}{|c|c|}
\hline Country & Respondents \\
\hline Australia & 1 \\
\hline Austria & 4 \\
\hline Belgium & 21 \\
\hline Brazil & 1 \\
\hline Bulgaria & 3 \\
\hline Canada & 6 \\
\hline China & 1 \\
\hline Croatia & 1 \\
\hline Czech Republic & 1 \\
\hline Denmark & 21 \\
\hline Egypt & 1 \\
\hline Estonia & 1 \\
\hline Finland & 11 \\
\hline France & 21 \\
\hline Germany & 46 \\
\hline Greece & 4 \\
\hline Hungary & 4 \\
\hline India & 13 \\
\hline Ireland & 8 \\
\hline Israel & 5 \\
\hline Italy & 75 \\
\hline The Netherlands & 16 \\
\hline Nigeria & 1 \\
\hline Norway & 1 \\
\hline Poland & 7 \\
\hline Portugal & 9 \\
\hline Romania & 7 \\
\hline Russia & 1 \\
\hline Serbia & 1 \\
\hline Slovakia & 1 \\
\hline Slovenia & 2 \\
\hline Spain & 44 \\
\hline Sweden & 13 \\
\hline Switzerland & 20 \\
\hline Ukraine & 1 \\
\hline The UK & 48 \\
\hline USA & 58 \\
\hline Not available & 6 \\
\hline
\end{tabular}




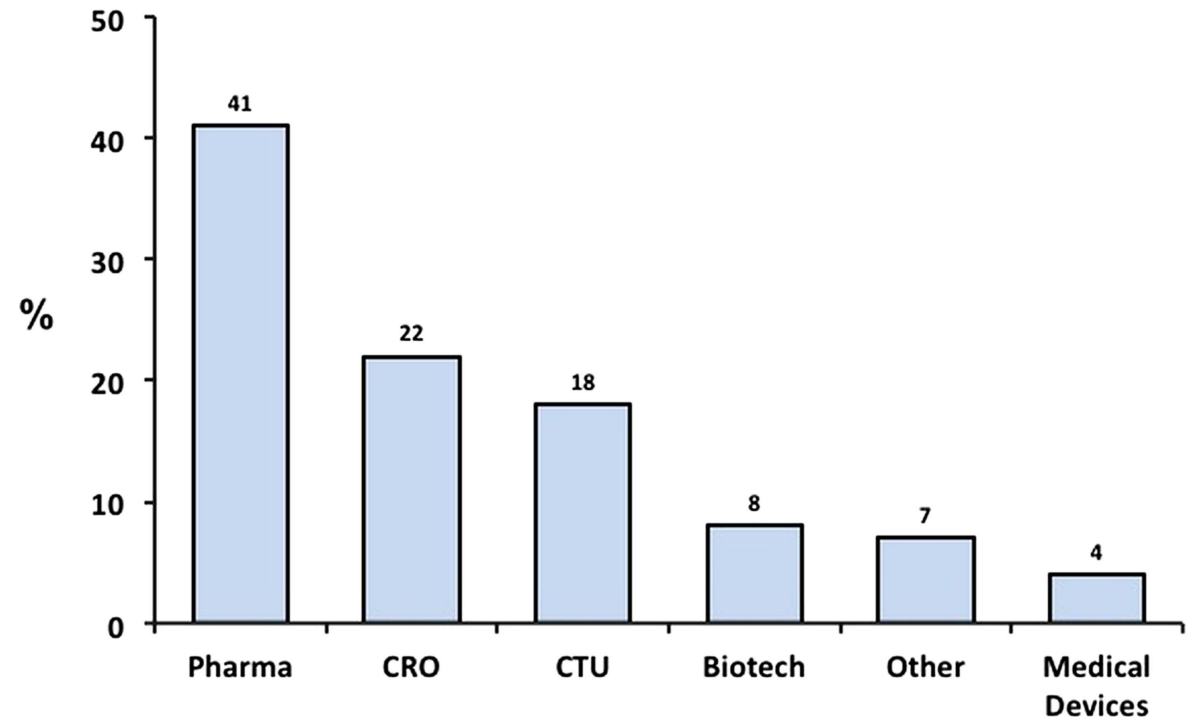

Figure 2 Respondent's organisation. Respondents were asked to answer the question: "Please indicate which organisation most closely resembles yours." Bars show percentage distribution of 485 individual responses. Biotech, biotechnology companies; CRO, clinical research organisation; CTU, clinical trial unit; medical devices, radiological, electromedical or healthcare information technology; pharma, pharmaceutical companies; other included following self-reported categories: respondent working for a mixed portfolio industry with either pharma/biotech portfolio or pharma/medical device portfolio (self reported); regulatory/clinical consultant, hospital or private clinic.

Relevance of investigator, environment, hospital and costs criteria

Respondents were asked to divide 100 points (reflecting their perceived level of importance) across four categories of factors impacting trial site selection. For early-phase and late-phase trials (as defined in the Methods section), factors pertaining to the investigator, the hospital/unit and the environment, were rated at a
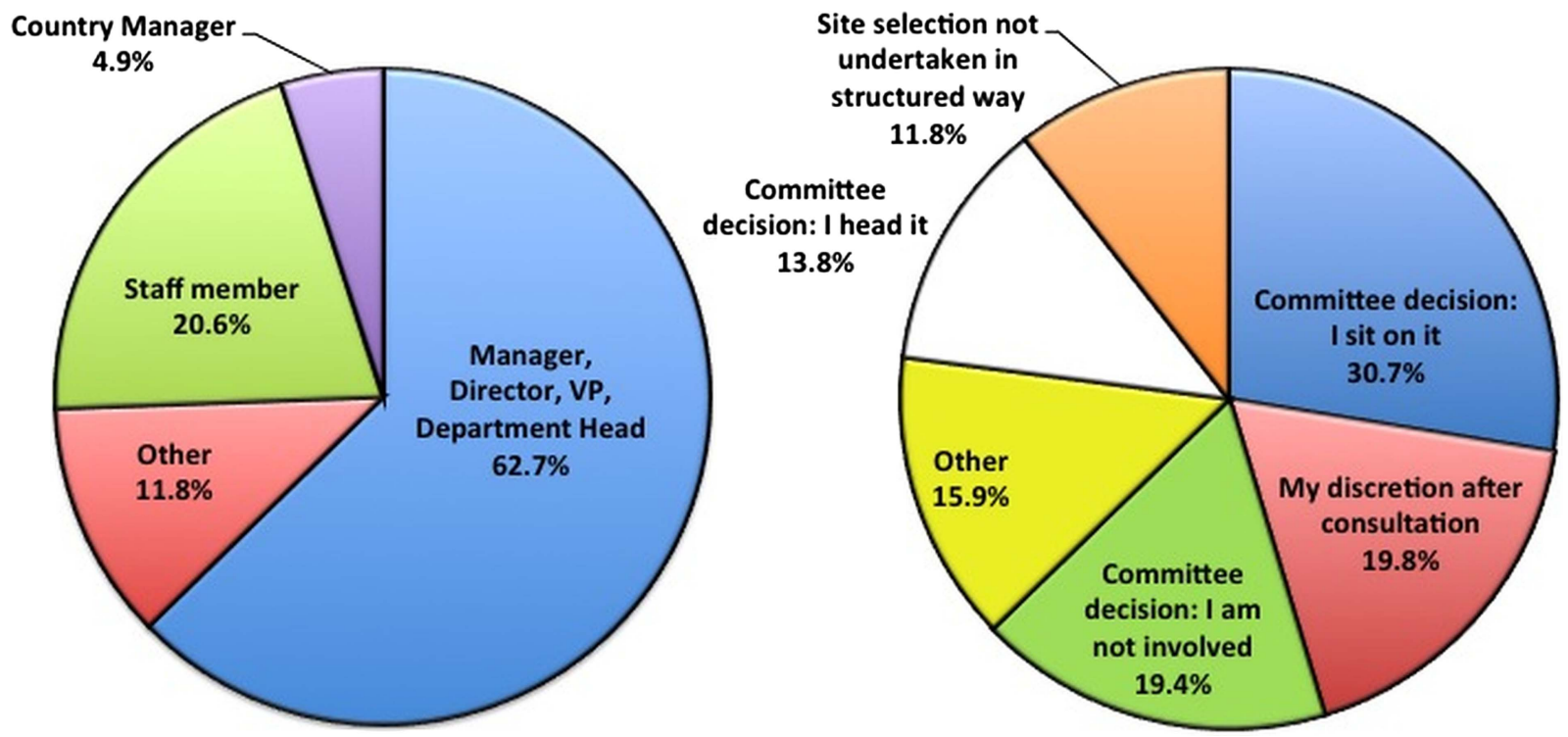

Figure 3 Left panel: respondent hierarchy. Respondents were asked to answer the question: "Please indicate the position which most closely resembles yours." Chart shows percentage distribution of 485 individual responses. VP, Vice President. 'Other' were respondents who wanted to be more specific in their titles: global study manager/clinical research associate (CRA); regulatory affairs/regulatory in a clinical department/good clinical practice quality assurance manager or director/safety pharmacovigilance officer; medical affairs/medical director/clinical director/global scientific affairs; and general manager. Right panel: respondent organisation's decision-making process. Respondents were asked to answer the question: "Please indicate which most closely resembles how trial site selection decisions are made at your institution." Chart shows percentage distribution of 485 individual responses. Other (11.8\%) included: my staff decides; decision outsourced to CRO; clinical research associate decides; decisions according to standard operating procedures; many people involved in decision; study team decides; our affiliates decide. 
high level of importance (25 or above; table 2). When combined, investigator-dependent and hospitaldependent levers were reported to be instrumental in trial site choice for early-phase and late-phase studies (average weight $60 / 100$ and $57 / 100$, respectively). In contrast, cost factors were considered to be less important for early-phase and late-trials $(\mathrm{p}<0.0001$; table 2$)$. This pattern of response was consistent across survey respondent groupings (ie, CTU vs CRO vs industry; not shown).

\section{Investigator-driven criteria}

Respondents were asked to assign 100 points across five investigator-related criteria. There was a statistically significant difference in the level of importance of the factors tested, with investigator track record in previous trials, experience in similar studies and interest in study scoring a level of importance of 20 or above, while concurrent trial workload, and publication track record were significantly less important $(p<0.0001$; table 3$)$. The pattern of response was again consistent across survey respondent groupings (not shown).

\section{Environment-driven criteria}

To explore environmental dynamics, respondents were asked to assign 100 points across six environment-related criteria. Market size/pool of eligible patients in the region, speed of approvals and presence of disease management networks, were assigned a greater level of importance. In contrast, costs of running trials, and particularly government financial/tax incentives were considered to be of significantly lower importance $(\mathrm{p}<0.0001$; table 4$)$. Also in this case, the pattern of response was consistent across survey respondent groupings (not shown).

\section{Hospital-driven criteria}

In this domain, 100 points had to be assigned across six criteria that explored characteristics of the specific hospital/unit where a clinical trial may potentially be run. There was a statistically significant difference in the level of importance of hospital-driven criteria, whereby site personnel experience and training, respondent's previous experience with site, and availability of facilities and equipment required by trial scored above 20 $(p<0.0001)$. In contrast, site personnel language capabilities and hospital quality assurance processes were significantly less important (table 5).

\section{Perception of European trial environment}

Our survey showed a statistically significant difference in respondents' perceived desirability of running clinical trials across the 12 European countries tested, that is, Europe's top five healthcare markets (Germany, France, Italy, the UK and Spain), large east European markets (Poland, Hungary and Czech Republic), plus the Netherlands, Belgium, Switzerland and Austria. For accessibility and transparency of all information required to run clinical trials (figure 4, upper panel), and availability of equipment (not shown), Germany, the UK and the Netherlands were the top three scorers. With regard to predictability and speed of ethics committees, Belgium was the top scorer, followed by Germany and the Netherlands (figure 4, lower panel). In terms of overall trial site 'desirability', respondents scored Germany as the most desirable trial location, followed by the Netherlands and the UK ( $p=0.0001$; figure 5) .

\section{Possible improvements}

Two questions tested the hypothesis that making a site more visible would be desirable from the decisionmakers' perspective. We found that $83 \%$ of respondents would have been 'much more likely' to include a site if all relevant investigator-related and hospital-related information were readily available (figure 6 , left panel). Furthermore, $75 \%$ believed that web-site information would be either 'definitely welcome', or 'useful most of the time' (figure 6, right panel).

\section{DISCUSSION}

The SAT-EU Study was a web-based survey designed to identify perceived drivers and hurdles associated with conducting clinical trials in Europe. We obtained

Table 2 Levers impacting trial site selection for early and late trials

\begin{tabular}{|c|c|c|c|c|c|c|}
\hline \multirow[b]{2}{*}{ Lever } & \multicolumn{2}{|c|}{ Response mean } & \multicolumn{2}{|c|}{ Upper 95\% CL } & \multicolumn{2}{|c|}{ Lower 95\% CL } \\
\hline & Early phase & Late phase & Early phase & Late phase & Early phase & Late phase \\
\hline Investigator factors & 30.2 & 29.1 & 31.5 & 30.4 & 28.9 & 27.8 \\
\hline Hospital/unit factors & 28.4 & 28.3 & 29.7 & 29.7 & 27.0 & 26.9 \\
\hline Environmental factors & 25.5 & 23.5 & 26.6 & 24.7 & 24.3 & 22.4 \\
\hline Cost factors & 16.0 & 19.0 & 17.2 & 20.4 & 14.7 & 17.7 \\
\hline
\end{tabular}

Respondents $(\mathrm{N}=341)$ were asked to divide 100 points across the above four levers impacting their trial site selection for early phase studies: Pharma, Biotech, CROs and CTUs answered for phase II (2) studies. Medical device and all others answered for phase III (3) studies. Then respondents were asked to do the same as above for later phase studies: Pharma, Biotech, CROs and CTUs answered for phase III (3) studies. Medical device and all others answered for phase IV (4) studies. There was evidence of a statistically significant difference in the level of importance of the four factors $(p<0.0001)$. The pattern of response (not shown here) appeared to be consistent across survey respondent groupings (ie, CTU vs CRO vs industry).

$\mathrm{CL}$, confidence limit; CROs, clinical research organisations; CTUs, clinical trial units. 
Table 3 Investigator-driven criteria in the selection of phase II-III trial sites (phase III-IV for medical device)

\begin{tabular}{|c|c|c|c|c|}
\hline Criteria & Mean & Upper $95 \%$ CL & Lower $95 \%$ CL & SD \\
\hline Investigator recruitment/retention track record & 27.3 & 28.5 & 22.4 & 13.3 \\
\hline Investigator experience in previous trials & 22.7 & 23.8 & 21.6 & 12.0 \\
\hline Investigator interest & 22.42 & 23.6 & 21.3 & 13.4 \\
\hline Investigator concurrent workload & 17.2 & 18.2 & 16.2 & 9.8 \\
\hline Investigator publication track record & 10.4 & 11.3 & 9.6 & 10.9 \\
\hline
\end{tabular}

Respondents ( $\mathrm{N}=341)$ were asked to divide 100 points across the above five criteria when selecting trial sites for phase III/IV (3/4) studies: Pharma, Biotech, CROs and CTUs answered for phase III (3) studies. Medical device and all others answered for phase IV (4) studies. There was evidence of a statistically significant difference in the level of importance of the five criteria $(p<0.0001)$. The pattern of response (not shown here) appeared to be consistent across survey respondent groupings (ie, CTU vs CRO vs industry).

$\mathrm{CL}$, confidence limit; CROs, clinical research organisations; CTUs, clinical trial units.

responses from over 400 participants in key stakeholder groups, that is, BioPharma industry, medical device manufacturers, CROs and CTUs. The vast majority of countries actively involved in clinical trials were represented, while most respondents were key decision-makers in their organisations. These features allowed us to get direct and potentially relevant insights into the reasoning behind site selection for clinical trials.

Recent years have seen much public policy discussion on the need to foster Europe's role in medical research, and to rekindle its dwindling attractiveness for investment in clinical trials. ${ }^{18-20}$ Various strategies have been proposed based on a 'common sense' approach. While possibly sound, policy recommendations were typically not founded on a systematic understanding of factors impacting clinical trial site selection. Indeed, one could argue that, borrowing from the rigour of its own discipline, medical policy decisions at all levels ought to be 'evidence based'. Regretfully however, this approach seems to be largely absent. To our knowledge, the SAT-EU Study is the first effort aimed at systematically investigating factors impacting trial site attractiveness across Europe. Given the survey's size, the variety of domains explored, the number of countries and organisations involved, and the prevalence of senior decisionmakers, our results may provide insight into 'real world' trial site decisions.

Our study has several key findings. First, there was evidence of considerable variability in the perceived receptivity of European countries to undertake clinical trials, Germany, the UK and the Netherlands being rated the best markets. Reasons for greater appeal of certain countries are multiple. Larger countries could be more attractive because of greater patient recruitment potential, and in prospect, because of the size of their markets. However, country size does not entirely explain the phenomenon, given the excellent results of small countries such as the Netherlands, and the low score of large countries such as Italy or Spain. Our survey sheds some light on this by pointing to the negative impact of administrative burden on clinical trial competitiveness. This is not only a concern at country level. Central to this discussion is the notion that the time required to collect information to determine a site's feasibility for inclusion in a trial, and to get it started, is also critical. Hence, the high weight placed on a site's proven track record in efficiently delivering results, which bears a relationship to specialised clinical research centres, and equally important, to the ability of clinical trial sponsors and organisers to access all of the required information quickly and effectively. Accordingly, the downsides of operating within a suboptimal regulatory environment may not prejudice selection of an otherwise visible and competent investigator, whose trial site information is readily available and who is able to recruit the required patients. A third important finding of our survey is that contrary to a widely held tenet, costs of running trialsoften invoked to explain why industry is going outside Europe $^{6}{ }^{16}$ _as well as government incentives/tax breaks, are not the main considerations when selecting European sites. In other words, it would seem from stakeholders' feedback and follow-up discussions that to

Table 4 Environment-driven criteria in the selection of phase II-III trial sites (phase III-IV for medical devices)

\begin{tabular}{|c|c|c|c|c|}
\hline Criteria & Mean & Upper $95 \%$ CL & Lower $95 \%$ CL & SD \\
\hline Size of market/eligible patients in a region & 23.8 & 25.2 & 22.4 & 13.3 \\
\hline Speed of MoH/ethics committees approval & 23.4 & 24.6 & 22.1 & 12.0 \\
\hline Disease management system/networks & 18.9 & 20.4 & 17.5 & 13.4 \\
\hline Cost of running trial & 15.2 & 16.3 & 14.2 & 9.8 \\
\hline Presence of country on 'core country list' & 11.8 & 13.0 & 10.7 & 10.9 \\
\hline Government financial/tax incentives & 6.9 & 7.6 & 6.2 & 6.6 \\
\hline
\end{tabular}


Table 5 Hospital-driven criteria in the selection of phase II-III trial sites (phase III-IV for medical devices)

\begin{tabular}{llll}
\hline & Mean & Upper 95\% CL & Lower 95\% CL \\
\hline Site personnel experience and training & 22.0 & 23.1 & 20.84 \\
Previous experience with site & 20.0 & 21.2 & 18.7 \\
Facilities/equipment required by trial & 19.7 & 20.7 & 18.7 \\
Hospital approval/contracting system & 17.4 & 18.5 & 16.4 \\
Site personnel language proficiency & 10.8 & 1.7 & 10.0 \\
Hospital quality assurance process & 10.1 & 9.2 \\
\hline Respondents (N=341) were asked to rate hospital-driven criteria by dividing 100 points across six criteria potentially used when selecting trial \\
sites for phase III studies: Pharma, Biotech, CROs and CTUs answered for phase III studies. Medical device and all others answered for \\
phase IV studies. There was evidence of a statistically significant difference in the level of importance of the six criteria (p<0.0001).
\end{tabular}

the extent that European centres may be excluded from a trial, the likely culprit is the hidden costs associated with excessive administrative time required to get a trial site up and running, not the high fees per enrolled patient. Although apparently surprising, the limited impact of costs needs to be considered against the backdrop of the various issues to which our survey tried to provide a response. Indeed, in addition to 'direct' costs, a major negative factor is represented by indirect, or 'hidden' costs, such as those characterised by time lost through layers of bureaucracy, slow recruitment by sites or poor overall site performance. Hence, the importance of not only bureaucracy, but also of the level of training and trial expertise at sites. Additionally, the notion that investments in clinical trials in Europe cannot be easily improved through government
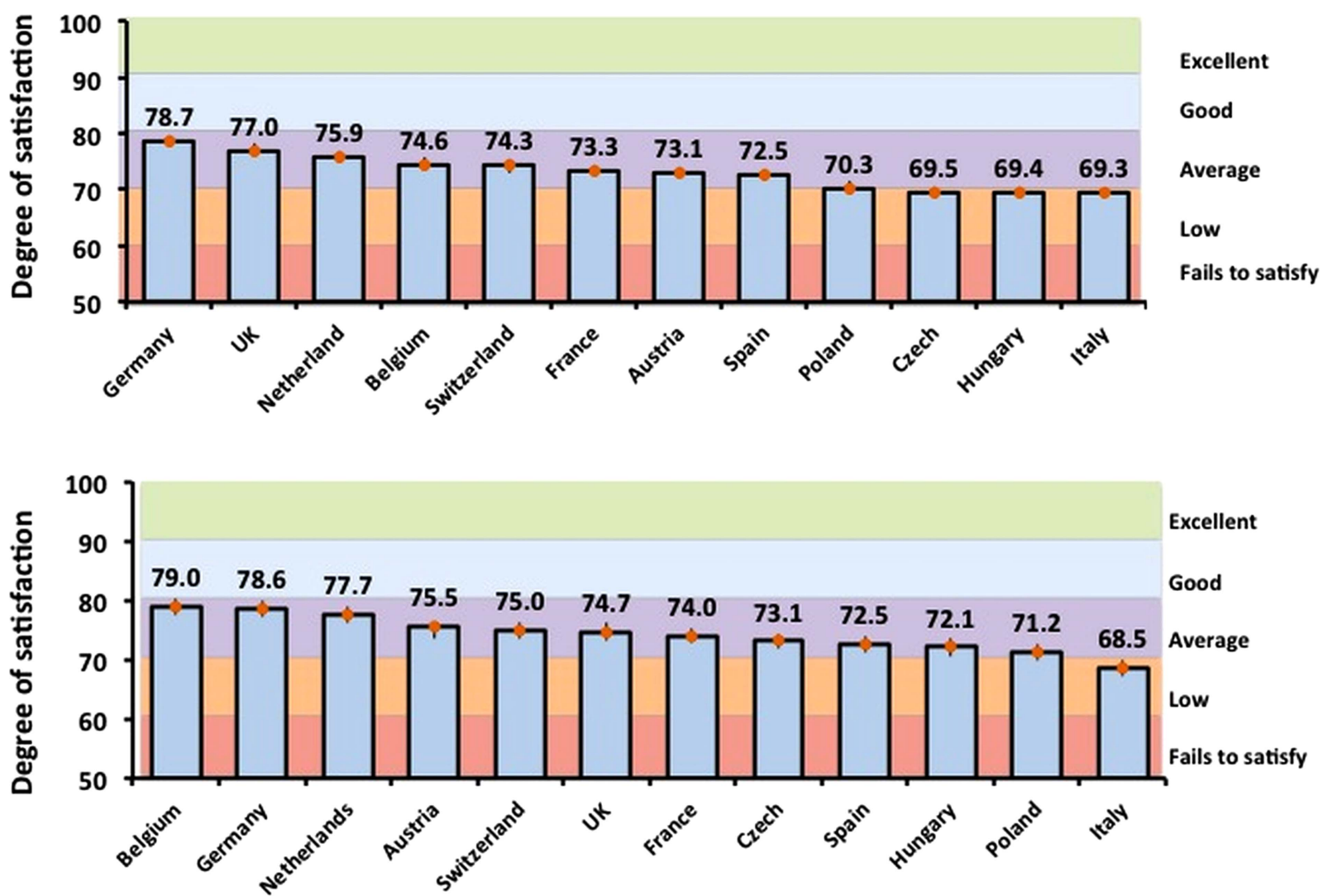

Figure 4 Upper panel: accessibility and transparency of all types of information required to make trial site selection decisions12 country rank $(\mathrm{N}=296)$. Respondents were asked to rate 12 countries for the accessibility and transparency of information (of all types) required to make trial site selection. Bars represent mean and $95 \% \mathrm{Cl}$. Statistically significant difference in satisfaction across European Union (EU) countries ( $p=0.0001)$. Lower panel: predictability and speed of ethics committees and institutional review boards (IRBs) for phase II-III multicentre randomised controlled trials (RCTs) -12 country rank ( $\mathrm{N}=296)$. Respondents were asked to rate 12 countries for the speed of their ethics committees and Institutional Review Boards for phase III (3) multicentric RCTs. Bars represent mean and $95 \% \mathrm{Cl}$ (number of respondents in parentheses). Statistically significant difference in satisfaction across EU countries $(p=0.0001)$. 


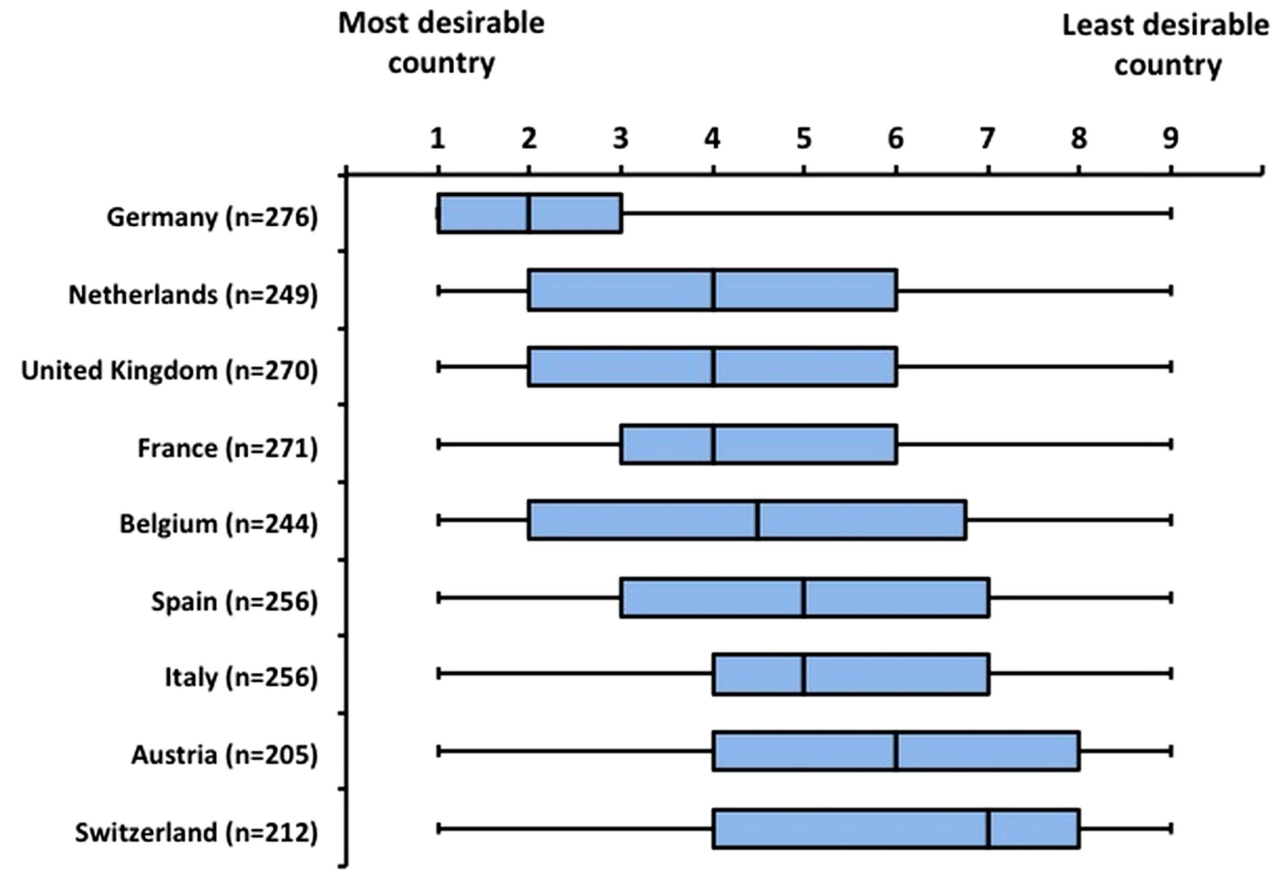

Figure 5 Trial site desirability by country. Trial site desirability 'index'-nine country rank (N=296; ordered by median). Respondents were asked to provide their 'personal perception' ranking of the desirability of running trials in nine countries, ranking them from ' 1 ' 'most desirable' country to ' 9 ' 'least desirable' country (if needed, they could click 'no opinion' in up to three countries they know the least). Data are presented as whisker-box plot of median and lower and upper quartile. There was evidence of a statistically significant difference in the perceived desirability of running trials across European Union countries $(p=0.0001)$.

incentives or tax breaks may have important implications in terms of public policy. Comments obtained through our survey seem to indicate that stakeholders would like a single European 'trial market' allowing them to gear trial site selection to expert investigators and to optimal patient recruitment, unobstructed by heterogeneous regulations or hurdles in obtaining crucial information.
Participants expressed this need in two main ways. First, from a regulatory or 'macro' perspective, they expressed desire for easier approval processes with less national variability and stronger pan-European element. This may indicate ethical committee approval timeframes, as well as institutional approvals at site level. Second, from a clinical research or 'micro' perspective, respondents

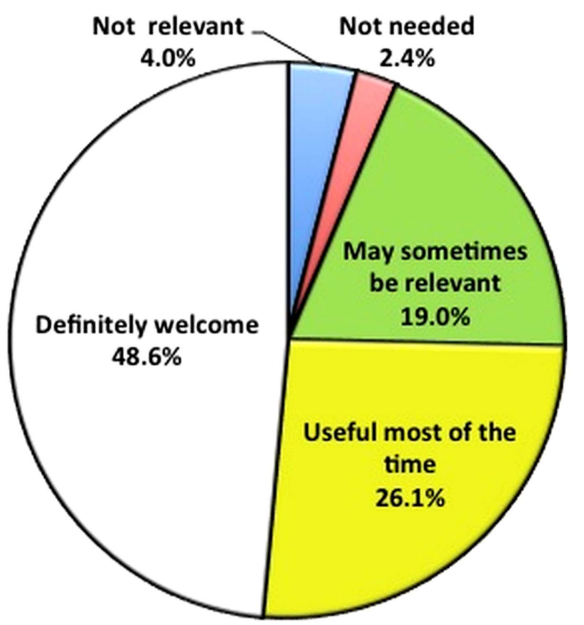

Figure 6 Left panel: likelihood of selecting trial site given relevant information. Respondents were asked to rate their level of agreement with the statement: "I am much more likely to select a trial site if I have all of the relevant Investigator and Site specific information easily available to me." Chart represents percentage response $(\mathrm{N}=253)$. Right panel: usefulness of trial site website information. Respondents were asked to pick the statement that they felt closest to with reference to the assertion that "it would be useful to have relevant trial information readily visible in a dedicated public section the Hospital's website (facilities, equipment, personnel qualification, Ethics Committee and Institutional Review Board timings, contact people for trials, etc)." 
want access to transnational networks of disease-area experts, through visibility of experienced trial units via the internet and/or via participation in disease networks.

More than 50 years ago, the founders of the EU envisioned a single market at the core of the European project. Despite this, a 'single market' vision for clinical research did not develop as envisaged. This is damaging to an industry in which much of the investment in clinical trials is by necessity multinationals. Indeed, Europe's 2020 growth strategy calls for 3\% of its Gross National Product to be invested in research and development (R\&D) by $2020 .^{21}$ If this goal is to be achieved, BioPharma-the European sector with the highest R\&D/ sales ratio $^{22}$ - should be allowed to invest in Europe without facing unnecessary roadblocks. Given the size of its healthcare market, its ageing population, its wellestablished pharmaceutical industry and the quality of its research centres and investigators, Europe has a formidable comparative advantage in clinical research. Individual European member states are well poised to take advantage of this by making the EU more competitive in clinical research. They should be encouraged to do so, not simply by investing in incentives or tax breaks, but by implementing revisions to the CTD that are under consideration by member states, and by legislating removal of unhelpful bureaucratic barriers at national level. Improving hospital contracting, such as via national or even pan-European contract templates, would also significantly reduce administrative burden, speed up trial start and make the European landscape significantly more competitive. On their part, the research community and relevant national bodies have a parallel imperative to ensure that hospitals and institutions are organised and networked more effectively, and that there is adequate training of trial staff. They need to ensure that clinical centres wishing to undertake more research are made more visible to industry and to international research communities, through dedicated research portals on their websites, or by creating and/or joining disease networks. Finally, given that selected countries are consistently scored above others, a best practice audit of administrative provisions governing and supporting clinical trials in countries such as Germany, the UK and the Netherlands ${ }^{14}$ would be helpful for drawing policy implications for other countries. The case for action rests on the realisation that evidence-based policy is indeed possible in this arena. Learning from what is working successfully will facilitate the road to creating a more welcoming environment for clinical research in Europe.

\section{LIMITATIONS}

Consistent with voluntary surveys, we could only analyse responses provided by those who were interested in replying, and therefore we cannot exclude that other points of view may have emerged from those who did not participate. Nonetheless, it is rather reassuring that the responses were gathered through a fairly large number of professionals who belonged to a variety of organisations from a number of countries, and who were for the most part the final decision-makers in the process. However, given that participation was largely through professional bodies and web-based communities, we are unable to provide an estimate of our coverage. While we took care in designing a survey that focused on the key determinants of trial site selection, we may have missed potentially important issues. We tried to minimise this through preliminary survey review and refinement with the help of external experts. Also, although we aimed at obtaining data relative to industrysponsored and not-for-profit clinical trials, it is possible that responses preferentially captured the former. In addition, some of our questions relating to process and speed of approval may need further research to determine the root issues, as problems differ from country to country, and have to be weighed against the need to ensure that patient safety remains unprejudiced.

\section{CONCLUSIONS}

Our study indicates that fostering European clinical research and attracting more trials to Europe does not require additional government spending. Instead, we believe our findings support a more harmonised national adoption of the clinical trial approvals process, greater visibility of transnational networks of disease experts, and greater accessibility to research system at national and pan-European levels. Potential models for improvement include harmonisation of ethical and institutional approvals systems, including aligned hospital contracting and greater visibility of centres of excellence, which may bring significantly more clinical research to Europe. Europe needs growth, and clinical research can play its part in directly stimulating economic activity while simultaneously boosting European innovation.

Acknowledgements The SAT-EU Study group gratefully acknowledges the collaboration of the following organisations, industry, clinical trial associations and online communities in recruiting survey respondents: Applied Clinical Trials (ACT) http://www.appliedclinicaltrialsonline.com/; European Forum for Good Clinical Practice (EFGCP) http://www.efgcp.be; European Federation of Pharmaceutical Industry Associations (EFPIA) http://www. efpia.eu/; European Biotech Industry Association (EuropaBio) http://www.europabio.org/; Perugia University, Italy http://facolta.unipg.it/medicina/; Drug Information Association (DIA) http://www.diahome.org/DIAHome/Home.aspx; Virtuoso Consulting, Geneva, Switzerland http://www.virtuoso.ch/model.html; European Vision Institute Clinical Research Network (Disease Network) http://www.evicr.net; EUCOMED Clinical Trial Interest Group http://www.eucomed.be/; and Pharma IQ http://www.pharma-iq.com/. The coauthors also would like to thank Alen Mulabdic, PhD candidate at the Graduate Institute of the University of Geneva in Switzerland, for helping in preparation of the figures/review of the statistical analysis. The study group has received acknowledgement permission from each of the institutions acknowledged for having helped to collect survey participants.

Contributors MG participated in survey design and implementation, critical data analysis, manuscript drafting and overall project supervision. RST participated in survey design, statistical analysis and editing final version of the manuscript.

$\mathrm{MM}, \mathrm{BC}$ and AP participated in survey design and implementation, survey advertising and data collection, critical data analysis, and editing final version 
of the manuscript. GG participated in survey design and implementation, critical data analysis and editing final version of the manuscript. GA participated in survey design and implementation, critical data analysis, manuscript drafting and overall project supervision. All coauthors work in the area of healthcare, either academia or consulting and as such have all been, or are involved in, the initiation, execution or interpretation of clinical trials.

Funding This research received no specific grant from any funding agency in the public, commercial or not-for-profit sectors.

Competing interests The EuropaBio and the EFPIA reimbursed RST for statistical analysis and for travel to a single study meeting, respectively. All coauthors work in the area of healthcare, either academia or consulting, and as such have all been, or are involved in, the initiation, execution or interpretation of clinical trials. Accordingly, all coauthors have an intellectual/ academic interest in seeing the European Clinical trial industry enhance its competitiveness.

Provenance and peer review Not commissioned; externally peer reviewed.

Data sharing statement Extra data are available in the form of raw survey data, providing individual (blinded) responses for each of the 485 respondents. These data can be accessed either directly on the Survey Monkey platform or downloaded to excel from Survey Monkey. Our statistical analysis is also available on request. Extra data are available by emailing giuseppe.ambrosio@ospedale.perugia.it.

Open Access This is an Open Access article distributed in accordance with the Creative Commons Attribution Non Commercial (CC BY-NC 3.0) license, which permits others to distribute, remix, adapt, build upon this work noncommercially, and license their derivative works on different terms, provided the original work is properly cited and the use is non-commercial. See: http:// creativecommons.org/licenses/by-nc/3.0/

\section{REFERENCES}

1. Barroso JM. European renewal-State of the Union Address 2011. EU speech/11/607; 28 September 2011. http://europa.eu/rapid/ press-release_SPEECH-11-607_en.htm (accessed 1 Jul 2012).

2. Frewer LJ, Coles D, Champion K. et al. Has the European Clinical Trials Directive been a success? BMJ 2010;340:c1862.

3. The Innovative Medicines Initiative (IMI). European Commission and the European Federation of Pharmaceutical Industries and Associations (EFPIA). http://www.imi.europa.eu (accessed 1 Jul 2012).

4. The European Research Area. http://ec.europa.eu/research/era/ index_en.htm(accessed 6 Sep 2012).

5. European Union (EU) Clinical Trials Directive. http://ec.europa.eu/ health/human-use/clinical-trials/index_en.htm\#rlctd (accessed 6 Sep 2012).
6. European Commission. Proposal for a regulation of the European Parliament and of the Council on clinical trials on medicinal products for human use, and repealing Directive 2001/20/EC. COM (2012) 369 final;Brussels17.7.2012. http://ec.europa.eu/health/files/ clinicaltrials/2012_07/proposal/2012_07_proposal_en.pdf (accessed 17 Dec 2012).

7. Demotes-Mainard J, Ohmann C. European Clinical Research Infrastructures Network: promoting harmonisation and quality in European clinical research. Lancet 2005;365:107-8.

8. Stankovski L, Kubiak C, Demotes-Mainard J., et al. ECRIN: making multinational clinical trials inEuropeeasier. EJHP Practice-vol.15 2009/issue 6.

9. Hernandez R, Cooney M, Dualé C, et al. Harmonisation of ethics committees' practice in 10 European countries. J Med Ethics 2009;35:696-700

10. Kingmann I. Impact on Clinical Research of European Legislation (ICREL). HEALTH-F1-2007-201002, June 2009.

11. Hartmann M. Impact assessment of the European Clinical Trials Directive: a longitudinal, prospective, observational study analyzing patterns and trends in clinical drug trial applications submitted since 2001 to regulatory agencies in six EU countries. Trials 2012;13:53.

12. Revision of the EU Clinical Trials Directive-Adoption of the proposal for a 'Clinical Trials Regulation'-17 July 2012; http://ec. europa.eu/health/human-use/clinical-trials/\# (accessed 14 Jul 2013).

13. Clinical Research in Europe. Trials and tribulations. Lancet 2012;379:1764.

14. Kenter MJ, Cohen AF. Re-engineering the European Union Clinical Trials Directive. Lancet 2012;379:1765-7.

15. European Society of Cardiology position paper endorsing 2012 recommendations for revisions to the EU Clinical trials directive 2001. http://www.escardio.org/about/press/press-releases/pr-13/ Pages/esc-clinical-trials-directive-revisions.aspx?hit=dontmiss (accessed 13 Feb 2013)

16. European Parliament. Clinical trials in developing countries. European Parliament, Director General for External Policies, Policy Department Report, March 2009

17. See Acknowledgementsat the end of the paper

18. The Alliance for Biomedical Research in Europe. http://www. biomedeurope.org/ (accessed 27 Nov 2012).

19. European Infrastructure for Translational Medicines. http://www. eatris.eu/SitePages/home.aspx (accessed 27 Nov 2012).

20. Research and Innovation, the Seventh Framework Programme. European Commission. http://ec.europa.eu/research/fp7/index en. cfm?pg=health (accessed 27 Nov 2012).

21. Europe 2020 Growth Strategy. European Commission. http://ec.europa.eu/europe2020/index_en.htm (accessed 11 Jul2012).

22. The $2011 \mathrm{EU}$ Industrial R\&D Investment Scoreboard. European Commission. The Joint Research Centre (DG-JRC) and Research (DG-RTD). 2011. http://iri.jrc.ec.europa.eu/research/docs/2011/ SB2011.pdf (accessed 17 Dec 2012). 